\title{
OTRA VEZ EL DESEO. PARA PENSAR LA ENSEÑANZA DE LA FILOSOFÍA
}

\author{
Olga Grau Duhart \\ Universidad de Chile \\ ograu_2000@yahoo.com
}

\begin{abstract}
Resumen
Se propone pensar, en esta ponencia, la relación filosofía y enseñanza a partir de la pregunta de si el deseo por la filosofía puede ser enseñado, pregunta que se enmarca en la consideración más general sobre el deseo. Haciendo referencia a algunos tratamientos de carácter filosófico respecto del deseo, se intenta responder a la pregunta, urdiéndola también con cuestiones de género que nos permiten configurar ciertas coordenadas de menor recurrencia. Este enfoque puede contribuir a pensar un horizonte para la actualidad de la filosofía y de su enseñanza en un tiempo que requiere un cambio en la mirada para inventar el futuro. Para la reflexión señalada se recogen diversas fuentes procedentes de la tradición filosófica y del pensamiento contemporáneo.
\end{abstract}

Palabras clave: deseo, enseñanza de la filosofía, género.

\begin{abstract}
We ask whether, in the light of what we know about desire in general, it is possible to teach the desire for philosophy. We refer to philosophical thoughts about desire and try to answer the question by connecting it to gender studies which enable us to consider less familiar categories. This perspective contributes to build an horizon for contemporary philosophy and its teaching at a time that demands a novel look for the sake of creating the future. For this task we have included several sources from traditional and contemporary philosophy.
\end{abstract}

KEYWORDS: Desire, teaching philosophy, gender.

La pregunta por el deseo

10 He querido elaborar una reflexión ${ }^{1}$ a partir de algunas preguntas que han surgido en el contexto del Seminario de Grado que ofrezco en la Universidad de Chile referido a las relaciones posibles a indagar entre Filosofía y Educación. En el

1 Reflexión con ocasión del Foro: "Filosofía y Educación: la filosofía en el proyecto humano de educar”. II Congreso Internacional de Filosofía, San Juan, Argentina. Julio 2007. 
Seminario hemos considerado un conjunto de asuntos concernientes a la enseñanza de la filosofía, en un diálogo con una multiplicidad de filósofas y filósofos elegidos para ese efecto ${ }^{2}$ y con los propios estudiantes. En ese diálogo ha surgido una pregunta que quedó formulada del siguiente modo: ¿puede el deseo por la filosofía ser enseñado?

Dicha pregunta se hizo presente a partir de dos textos, uno de Lyotard “¿Por qué desear?" (Lyotard 1989) y otro de Cerletti "La enseñanza de la filosofía: de la pregunta filosófica a la propuesta metodológica"3, textos que remiten a su vez a otros textos. Lyotard envía al diálogo platónico El Banquete, en el que la filosofía se nos presenta como Eros, figura ambivalente que juega su oscilación entre la escasez y la abundancia, entre lo femenino y lo masculino, la vida y la muerte, en permanente tensión entre opuestos. Lyotard se hace acompañar con el diálogo platónico para elaborar posibles respuestas a la pregunta de por qué desear, entendiendo por deseo "la relación que simultáneamente une y separa sus términos, los hace estar el uno en el otro y a la vez el uno fuera del otro" (p. 89) Para Lyotard, "filosofar es dejarse llevar por el deseo, pero recogiéndolo, y esta recogida corre pareja con la palabra", siendo "el problema del Logos, de la palabra, (...) el de la reflexión del deseo sobre sí mismo". Así es como entonces, "Filosofar es obedecer plenamente al movimiento del deseo, estar comprendido en él e intentar comprenderlo a la vez sin salir de su cauce" (p. 99); "Filosofar no es desear la sabiduría sino desear el deseo" y en vez de buscar la sabiduría, Lyotard nos dice que más bien nos valdría buscar por qué buscamos (p. 95).

En el texto de Cerletti, que dialoga en algunos de sus planteamientos con el de Lyotard, encontramos la afirmación de que la filosofía, más que amor o deseo de saber, sería el deseo del deseo de saber. Sostiene, asimismo, que "el deseo de filosofar, como el deseo de pensar, es, en última instancia intransmisible", y "no es posible enseñar a "amar" la sabiduría, como, por cierto no es posible enseñar a enamorarse". De este modo, el deseo por la filosofía es inenseñable, existiría un límite para la enseñanza de la filosofía: el de la no existencia del deseo por la filosofía, el deseo de filosofía.

Mi pregunta mueve una pieza del ajedrez hacia la afirmación de Cerletti de que no se puede enseñar el deseo. A mi modo de ver, esta perspectiva podría clausurar la posibilidad de entender la escena pedagógica de la enseñanza de la filosofía como posible escena de seducción en el deseo por la filosofía.

Para abordar esta cuestión, quisiera partir por el principio, por la narración que nos ofrece el Génesis. El relato de Adán y Eva nos lleva a pensar en el emerger del

2 Sartre, Lyotard, Ranciére, Steiner, Foucault, Derrida, y amigos cercanos P. Vermeren, L. Cornu, W. Kohan, A. Cerletti, M. Berttolini, V. Waksman, M. López, H. Giannini, P. Oyarzún, C. Sánchez.

3 Intervención en el II Encuentro Internacional de Filosofía y Educación, Universidad del Estado de Río de Janeiro, Brasil. Texto me fue facilitado por Water Kohan en el año 2005. 
deseo, y el lugar, figura y modo de su ocurrencia ${ }^{4}$. El deseo de Eva por comer del fruto del árbol prohibido ¿es un deseo despertado o inducido? El deseo de Eva suscitado por la serpiente, ¿es el primer deseo? ¿Nos dice este relato que es el deseo lo que constituye lo humano? ¿Es el deseo su caída? ¿Se cae en el deseo?

La serpiente, a mi modo de ver, introduce el deseo en Eva, perfora su inocencia, invitándola a ser como diosa, no solo inmortal, sino conocedora del bien y del mal. La palabra de Dios ha instituido el mandato, la prohibición; en cambio, la palabra de la serpiente es promesa de poder, saber y vida ilimitados, realizable a través de la acción de comer un objeto, el fruto del árbol prohibido. Dos formas del dominio de la palabra. La palabra de Dios ha instituido el mandato, la prohibición. La de la serpiente tienta, tantea, enarbola el deseo, remontando la inocencia, pone una mala fe, un descreimiento en la ley, atrae hacia lo que falta. La palabra serpentina suscita el deseo al mismo tiempo que produce lo deseable, la deseabilidad del saber, asociado al poder e inmortalidad, negado, prohibido, impedido. Por ello, con ese primer objeto deseado se accede a la experiencia del deseo de lo absoluto, condición constitutiva del primer deseo. La palabra serpentina serpentea el deseo, lo provoca, produce imágenes de situaciones posibles que se hacen deseables, ofrece una escena imaginaria que prefigura otro mundo factible. El mundo que ofrece la serpiente, además del de poderío absoluto imaginable es el (saber) de la comparación, la diferencia (bien y mal), que se modelará a partir de la diferencia sexual. Luego de la pérdida del paraíso, lo humano queda lanzado al deseo de retorno al no deseo (jardín paradisíaco) y a lo indiferenciado.

La serpiente es mediadora entre la inexistencia del deseo por imposición de la ley y mandato divinos y la existencia del deseo. La mordida es ya el deseo de saber, es un acto ya no desde la inocencia, sino desde el deseo. En la inocencia, podríamos decir, no hay deseo. El deseo se vincula fuertemente a la transgresión, a un estado de alteración de determinadas condiciones, de lo dado, de lo dictado; irrumpe en la escena de la trasgresión que no es sino trascender la limitación existente respecto de una experiencia (im)posible que se hace deseable.

A través de la seducción, el árbol se ve como bueno y deseable. "Vio pues, la mujer que el árbol era bueno para comerse...y deseable para alcanzar por él la sabiduría”. El deseo prepara el saber, pero también el deseo ya sabe, sabe como ficción, por imágenes. Ya se sabe antes de comer el fruto que éste es bueno para comerse y ya se sabe también algo en el acto mismo de la mordida. La mordida es saber del bien por venir prometido por la serpiente, es deseo de saber (lo deseable), y es también saber del deseo. Pero el saber de la distinción del bien y del mal, de la diferencia, saber prohibido, solo se da en el comer y tragar, compartido por Adán y Eva; se trata de dar sitio en el cuerpo al fruto del árbol. Y el primer saber de la distinción es el saber de la

$4 \quad$ Una reflexión anterior a propósito del mismo relato que abordó el tema, entre otros, del deseo, fue escrita en mi ensayo "Desde el revés: mujer y poder”, en Grau 1992. Respecto del desarrollo hecho en esa ocasión tengo algunos puntos de diferencia. 
diferencia sexual, que se manifiesta en la vergüenza de la desnudez. Saber corporal, entonces; se sabe con el cuerpo y se sabe del cuerpo. Asistimos en el relato bíblico a la carnalización del deseo. Pareciera ser, en esta comprensión, que no nos podemos desprender cuando nos referimos al deseo de su connotación erótica.

Algo completamente distinto de esta interpretación del relato bíblico ocurre en el contenido del enunciado aristotélico de que "Todos los hombres desean naturalmente el saber". Allí, la inclinación al saber está dada por naturaleza. El deseo no requeriría de la palabra mediadora para ser producido, está dado ya en la simple observación de que son capaces los ojos, un saber de actualidad. Se está desde siempre y para siempre en el deseo de saber que puede ir cobrando formas más complejas hasta el deseo de saber metafísico. El primer grado de saber, es también el primer grado de ese deseo. La curiosidad en el observar, en el relacionar a partir de las percepciones, no podría faltar en el ser humano, sería el primer grado. Este primer grado del deseo es también animal, dadas las semejanzas que establece Aristóteles en este punto entre humanos y animales.

En nuestro tiempo, se tiene todavía la idea de que tenemos instintos, inclinaciones básicas por determinados objetos, dispositivos que disparan hacia determinadas acciones espontáneas. Pero más bien la existencia humana, en la medida en que incorpora fuertemente la socialización y la culturización, no se arma en base a instintos o mecanismos de carácter natural, sino a condiciones primarias de esa misma culturización que es también producción de las formas y articulaciones de los deseos ${ }^{5}$.

Como muy bien lo ha expresado la filósofa feminista Butler, el deseo es una cuestión política y también filosófica. Nos dice Butler: "Pero políticamente es importante que la gente se pregunte ‘¿Qué es posible?' Y que crean en la posibilidad. Porque sin el movimiento de la posibilidad, no hay movimiento hacia adelante. (...) La filosofía hace pensar a la gente en posibles papeles, les proporciona una oportunidad de pensar el mundo como si fuera de otra forma. Y la gente lo necesita" ". Por su parte, Deleuze afirma: "el deseo no es nunca una determinación "natural", ni "espontánea"

Podríamos decir que el deseo tiene muchas formas, y no sabemos de ellas porque no las hemos recorrido, determinados en nuestros deseos muy unilateralmente por los mandatos culturales, por las instituciones de todo tipo. No sabemos de ciertos

5 Solo podríamos hablar tal vez de instintos en un humano que ha sido abandonado a la naturaleza, en la más completa separación de sus congéneres, solo acogido por animales que le ayudan a sobrevivir. E incluso allí, no sabemos qué lugar tiene en la memoria genética una historia biopolítica.

6 Entrevista a Judith Buttler: "El deseo y la filosofía”.Entrevista realizada por Regina Michalik (LOLApress) durante la estadía de la filósofa en Berlín, en mayo de 2001, por invitación de la Academia Americana.

$7 \quad$ Magazine Littéraire, $\mathrm{n}^{\circ} 325$ (número dedicado a Foucault), octubre 1994, pp. 57-65. 
deseos, porque no los hemos concebido o no los hemos hecho carne ${ }^{8}$. El deseo atisbado o recorrido en alguna de sus vías puede ser explorado y expandido en sus variaciones, pero también el deseo puede ser creado, producido en un determinado momento, y en la medida en que lo creo e invento, lo descubro, lo descubro en su particularidad. No está dado previamente, pero tampoco es la permanente y completa ausencia.

\section{Deseos menores y mayores}

"Arriba, arriba", decía un niño para indicar los objetos de su deseo, y su dedo no indicaba lo trascendental o celestial como el dedo platónico en versión de Rafael, sino más bien señalaba la ubicación espacial que tenían en el mueble de la cocina los objetos para él inalcanzables y preciados gracias a su sabor placentero ya probado por el pequeño. Pero, con el tiempo, la palabra arriba comenzó a aludir a algo indefinido, era el nombre de algo que se deseaba, pero que no tenía forma y, por tanto, inidentificable. La palabra vino a nombrar algo que faltaba, que se sentía como falta, pero era también la afirmación de todo el continente de los objetos posibles, materiales e inmateriales. El niño podía caminar ansiosamente por la casa, en medio de personas y cosas, con esa palabra en la boca que, nombrada una y otra vez, parecía convertirse en la materia misma de su deseo. Su deseo hecho palabra, hecho de palabra, concretizado como bocado.

Esta pequeña historia da que pensar sobre el deseo y nos lleva a preguntarnos si es posible hablar de deseo cuando éste no tiene un objeto referencial, o si es ésa más bien la condición fundamental del deseo. Podríamos distinguir los deseos entre unos que poseen un objeto definido, deseos menores que buscan su satisfacción aunque pueda ser incluso en medio de penurias, y otros que no tienen un objeto de figura propia, deseos mayores, a mi entender. Sin embargo, tanto unos como otros mueven la voluntad, en un caso dirigida, apegada a una representación buscando su satisfacción que colmada hace morir al deseo, y en el otro caso, disparada al infinito.

Otro punto de unión que tienen los deseos menores y mayores, desde la nomenclatura ideada, se puede dar cuando los menores son excesivos, son conducidos o más bien compelidos por un imaginario de lo inconmensurable, del desborde, del colmo, del éxtasis que en la culminación del deseo lo deja en el olvido. Los deseos mayores en la vaciedad de objetos inquietan el alma, le imprimen una tensión ansiosa, la deprimen o la exaltan, la mueven o la paralizan. Basta un pequeño movimiento de giro en el ánimo del deseante mayor para que en lo indefinido comparezca la sombra

$8 \quad$ En esto, los estudios gays y lésbicos han aportado miradas interesantes, refiriéndose a la dictadura heterosexual (Sheeley Jefreys), o heterosexualidad obligatoria, en Adrianne Rich. Deleuze, por su parte, al señalar que el deseo no es una "realidad natural" coincidiría con las feministas que postulan la diversidad multifacética del deseo sexual. 
de un algo que, como sombra, no permitirá la materialización del deseo que seguirá en su errancia, entre la nada y el todo.

El deseo sadiano que busca en las operaciones técnicas de satisfacción su posibilidad de realización puede servirnos para pensar el cómo se transita de un deseo menor a un deseo mayor: la doncella en La filosofía del tocador iniciada en el deseo sexual logra la metamorfosis a través de la expurgación de la virtud, del abandono de la crisálida virtuosa de matriz materna en que ha estado atrapada, en una sucesión de actos aprendidos, que van extremando sus capacidades de goce, que culminan en el acto de coser el lugar de su propio origen, de su llegada al mundo, la abertura genital del cuerpo de la madre, acto ya no indicado por su maestro, sino dictado por sí misma. Deseo del propio cuerpo realizado en el cuerpo de la madre, en un gesto de negación afirmación, en la intersección de la nada y el todo. Los actos sadianos buscando el extremo de su goce no alcanzan jamás lo vinculante, niegan el vínculo, por su carácter espurio de limitar la libertad del deseo mayor.

Vincent Descombes piensa el problema del deseo en un ensayo breve y sugerente, "El deseo" (Descombes s/f, pp. 41-48), donde alude a los pedagogos contemporáneos, cuyo problema no es tanto reprimir como "despertar", excitar en los niños el deseo de hacer lo que no saben hacer todavía, esto es, el deseo de aprender. Respecto de este planteamiento, tomaría distancia en tanto afirmo aquí en este escrito la producción del deseo más que su despertar, así como también el sentido mimético que en su reflexión cobra. Dice Descombes: "Así entendido, el deseo es una fuerza activa, productiva de nuevas potencialidades". Deseo que, a su juicio, es productivo en la medida en que es reproductivo, mimético de los éxitos de otro. Se les despierta a los niños el deseo activo, invitándoles a hacer algo tan bien como lo hace otro (p. 42).

\section{Digesto y salida}

Desde las afirmaciones que han llenado este texto, creo que podríamos ya señalar algunas claves para abordar el problema de enseñar el deseo por la filosofía: al parecer, lo inducimos, lo producimos, hacemos deseable el deseo de pensar, enseñamos el deseo del deseo de pensar. Este enseñar el deseo pasa por la seducción de que seamos capaces, de que el cuerpo hable y dé señas en su entusiasmo por pensar. Enseñar el deseo por la filosofía es mostrar al otro nuestro propio deseo, exponernos en nuestra vacilación, indicar el movimiento de incertidumbre.

La producción de deseo, como vimos, se vincula a la promesa, a algo que puede ser, pero que como deseo ya vale en su poder. ¿Qué promete la palabra filosófica, cuál es su promesa? Podría ser que prometiera una actualidad, la de una comprensión o conexión. No el deseo de absoluto, de completitud, sino deseo de potencia actual, la conciencia del presente pensante, el flujo de energía del poner en relación, de la experiencia de la infinita conexión posible de los pensamientos, de las cosas. El nada detenido, el todo en movimiento. No desear algo tan definido y definitivo, sino el movimiento del deseo, sentir ese ir y venir de él. Desear, amar el punto luminoso de 
algo que acontece en su incierto destino, y que tiene el fulgor de la actualidad, y donde nos acercamos a la experiencia de lo transitorio y a la vulnerabilidad del conocer. El deseo está siempre disparado, tiene como mundo propio un imaginario que puede pretenderse como factible, realizable, un contexto de posibilidad simplemente, dispuesto a su propia ruina.

Nuestro deseo occidental, el que nos han inducido y nos inducen permanentemente, es compulsivo, quiere todo lo que desea y lo quiere completamente. Enseñar el deseo de filosofar sea tal vez enseñar a no desear lo absoluto, o a desear sabiendo siempre de la fragilidad, del carácter efímero, contingente, actual, imprevisible, del contenido del deseo. Pensar (y enseñar) el deseo puede ser entendido no como algo a colmar, que nunca se logra, sino como la experiencia de lo ilusorio, de la ficción en que habitamos.

Enseñar la filosofía sería enseñar el deseo en el sentido de saber de él, enseñar una mirada cuestionadora que piensa las condiciones en que se desea, y cómo deseamos; que piensa los objetos que se han deseado en la filosofía, y la permanente apertura del espacio filosófico.

\section{Referencias bibliográficas}

Descombres, Vincent (s/f). Doce lecciones de Filosofia. Barcelona: Ediciones Juan Granica.

Grau, Olga, ed. (1992), Ver desde la mujer. La Morada: Editorial Cuarto Propio.

Lyotard, Jean-Francois (1989). ¿Por qué filosofar? Barcelona: Paidós. 